\title{
TANNINS OF DECIDUOUS TREES BARK AS A POTENTIAL SOURCE FOR OBTAINING ECOLOGICALLY SAFE WOOD ADHESIVES
}

\author{
Sarmite Janceva ${ }^{1}$, Tatiana Dizhbite ${ }^{1}$, Galina Telisheva ${ }^{1}$, Uldis Spulle ${ }^{2}$, \\ Laimonis Klavinsh ${ }^{2}$, Marcis Dzenis ${ }^{3}$ \\ 1- Latvian State Institute of Wood Chemistry, Dzerbenes st. 27, Riga, LV 1006, Latvia \\ E-mailligno@edi.lv \\ 2- Forest and wood product research and development institute \\ 3- Riga Technical University
}

\begin{abstract}
The bark of deciduous trees grown in Latvia: grey alder, black alder, ash tree and goat willow were sequentially extracted using solvents of increasing polarity. The data about total content of both lipophilic and hydrophilic compounds were obtained using sequentially extraction with hexane and ethanol. The highest yields of hydrophilic extractives were found for grey alder and ash tree barks $(25.7 \%$ and $25.8 \%$, respectively). Hydrophilic extract from the both alder species contained high amount (up to $12 \%$ on bark dry mass) of condensed tannins (CT)_or_oligomeric proanthocyanidins, whereas CT content of extract from ach tree was negligible. The main component of ethanol-water extract from alder bark was identified using ${ }^{13} \mathrm{C} N M R$ and MALDI-TOF MS spectroscopy as a mixture of A-and B-type oligomeric procyanidins with the epicatechin units polymerization degree of 2-7. Ecologically friendly wood adhesives were obtained on the condensed tannin basis.
\end{abstract}

Keywords: bark of deciduous trees, condensed tannins, proanthocyanidins, wood adhesive, free radical scavenging activity.

\section{Introduction}

The bark of deciduous tree species is scarcely explored as a source for obtaining of valuable extractives products. Grey alder, black alder, ash tree and goat willow cover, respectively, 6.8; 2.6; 3.4 and $0.7 \%$ of Latvian forest area. The composition of their bark extractives was not yet studied systematically. High portion (about 30\%) of proanthocyanidins, better known as condensed tannins (CT) in polyphenolic pool of alder bark [1] makes it a prospective raw material for not only for medicine and veterinary but also for industrial application. Such condensed tannins as "quebracho" are produced commercially from wood and bark of Schinopsis sp. trees and are often used as a raw material for the production of tanninformaldehyde wood adhesives [2]. Phenol-formaldehyde based wood adhesives still today dominant in European markets. However, toxic formaldehyde emission and necessity to diminish petrochemicals consumption stimulate the search of alternative environmentally safe adhesives. The antimicrobial properties of condensed tannins [3] make their application in wood composites and adhesives industry very attractive.

Proanthocyanidins are mixtures of oligomers and polymers composed of flavan-3-ol units linked mainly through C4-C8 or C4-C6 linkage (B-type) as well as the flavan-3-ol units can also be linked by an additional ether bond between C2-O-C7 (A-type). The size of proanthocyanidins molecule is described by the degree of polymerization (DP) [4].

The aim of the present work was screening of some widely spread in Latvia and Europe deciduous tree species: grey alder (Alnus incana), black alder (Alnus glutinosa), ash tree (Fraxinus excelsior), and goat willow (Salix caprea) as a potential source for CT obtaining and their testing in composition of formaldehyde free wood adhesives.

\section{Materials and methods}

The bark of deciduous trees samples were collected from the forest in the East-South part of Latvia. Samples were sequentially extracted with solid-liquid fluidized bed extractors IKA 
using solvents of increasing polarity: hexane, ethyl acetate and, finally, aqueous ethanol (1:1, $\mathrm{v} / \mathrm{v})$. The ethanol was removed under vaccuum and the remaining aqueous solutions were frozen and freeze-dried. The total amount of extractives was determined gravimetrically. Total phenolics content was determined by the Folin-Ciocalteu method [5] using gallic acid (Sigma-Aldrich) as a reference compound and condensed tannins content was measured by buthanol- $\mathrm{HCl}$ method using procyanidin dimer B2 (Extrasynthese) as a reference compound [6]. The condensed tannins were purified from non-tannin phenolics using Sephadex LH-20 [6]. ${ }^{13} \mathrm{C}-\mathrm{NMR}$ (Bruker Advance 300 spectrometer, $75 \mathrm{MHz}$ ) and TOF-MS (QSTAR Elite System Hybrid Quadrupole-TOF/MS) spectroscopies were used for characterization of proanthocyanidins isolated from alder bark.

Condensed tannins from grey alder bark were tested for their potential antioxidant activities using a 1,1-Diphenyl-2-picrylhydrazil (DPPH ${ }^{\bullet}$ ) (Sigma-Aldrich) assay. Trolox (6-hydroxy2,5,7,8-tetramethylchroman-2-carboxylic acid) (Sigma-Aldrich) was used as a reference standard. Test was performed spectrofotometrically [7], the inhibition percentage (IP) of $\mathrm{DPPH}^{\bullet}$ was calculated as:

$$
I P=\frac{\left(A_{B}-A_{A}\right)}{A_{B}} \times 100 \%,
$$

where $A_{B}$ is absorbance at $517 \mathrm{~nm}$ in blank probe (antioxidant was omitted) and $A_{A}$ is absorbance in the sample after $15 \mathrm{~min}$. The IP values were plotted as a function of the antioxidant concentration. From the graphs the antioxidant concentration needed to obtain $50 \%$ IP was determined and defined as $\mathrm{IC}_{50}$. According to the definition, higher antioxidant activity results in lower value of $\mathrm{IC}_{50}$.

The condensed tannins based adhesives were obtained by mixing of aqueous tannin solution $(\mathrm{pH} 7)$ with $50 \%$ (w/v) aqueous polyethylenimine (PEI) solution (Sigma-Aldrich) at $22^{\circ} \mathrm{C}$. The tannin adhesives were characterized by differential scanning calorimetry (DSC) using a Metter Toledo DSC 828 apparatus [8].

The resulting adhesives were tested for obtaining of plywood panels. Plywood panel samples were made using tree plies of birch (thickness of $2 \mathrm{~mm}$ each), and $170 \mathrm{~g} / \mathrm{m}^{2}$ of adhesive. The panels were pressed for 10 minutes at $140^{\circ} \mathrm{C}$ and pressure of $2 \mathrm{MPa}$. The samples obtained were conditioned in a climate room $\left(25^{\circ} \mathrm{C}\right.$ and $65 \%$ humidity) for $24 \mathrm{~h}$. Then the quality of plywood panel gluing was evaluated by the statistic bending (modulus of elasticity) and the bonding shear tests, carried out according to EN314 -1:2005 [9].

\section{Results and discussion}

The highest yield of hydrophilic extract was found for bark of grey alder and ash tree and lowest for goat willow (Figure 1). Grey alder bark is notable among investigated tree species not only by the highest total yield of hydrophilic extracts (36\% from o.d. bark) but also by the high content of polyphenolics in them (13-17\% from o.d. bark).

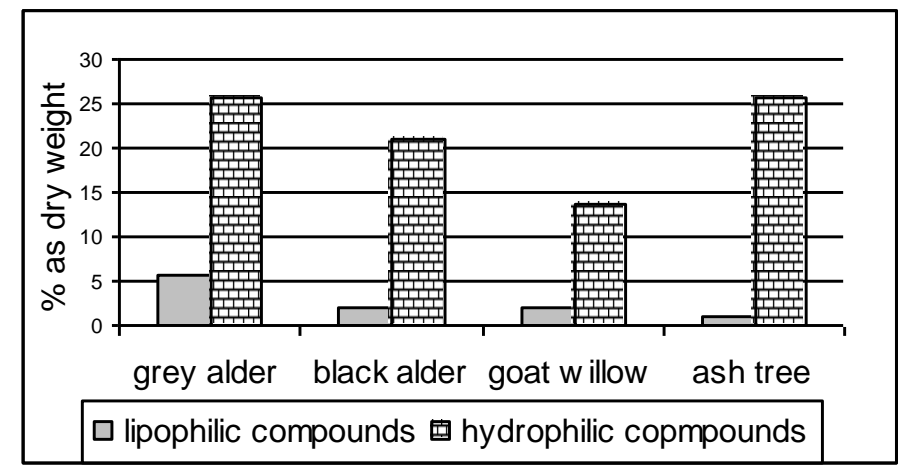

Fig.1. The yield of lipophilic and hydrophilic extractives (\% of oven dry bark) 
The butanol- $\mathrm{HCl}$ assay has greatest strength on confirmation of presence of a polymeric interflavan structure [6]. Hydrolyzable tannins do not react in this assay. The condensed tannins (proanthocyanidins) contents in the ethanol-water extracts of Alnus incana and Alnus glutinosa were $43.44 \%$ and $34.27 \%$, respectively. The hydrophilic extract from ash tree bark, unlike the grey alder and black alder bark, did not show positive reaction in butanol-HCl assay. This indicates the negligible $\mathrm{CT}$ content in $F$. excelsior bark. Purified proanthocyanidins from grey alder bark were analyzed by ${ }^{13} \mathrm{C}-\mathrm{NMR}$ spectroscopy. The NMR signals assignment was made based on the literature data [10].

The structural diversity of the linkage (A and B type) and stereoisomer of catechin and epicatechin units is apparent from the ${ }^{13} \mathrm{C}-\mathrm{NMR}$ spectrum (Figure 3). Specifically, C5, C7, and C8a carbons of procyanidins appear in the region 160-150 ppm. Peak at 144.4 belong to $\mathrm{C}^{\prime}$ ' and C4' of procyanidins units. The cluster of peaks between 110 and $90 \mathrm{ppm}$ is assigned to C8, C6, C6", C8" and C 2' of procyanidins. The region between 90 and $70 \mathrm{ppm}$ is sensitive to the stereochemistry of the $\mathrm{C}$ ring. The ratio of the 2,3-cis to 2,3-trans isomers could be determined through the distinct differences in their respective $\mathrm{C} 2$ chemical shifts. $\mathrm{C} 2$ gives a resonance at $75.3 \mathrm{ppm}$ for the cis form and $79 \mathrm{ppm}$ for the trans form, the cis isomer is dominant. $\mathrm{C} 3$ of both cis and trans isomers occurs at $71.5 \mathrm{ppm}$. The $\mathrm{C} 4$ atoms showed a peak between 37-29 ppm. The chemical shift of the ketal carbon (C2) formed as a result of additional bond observed at $100.9 \mathrm{ppm}$. The results suggested the presence of another interflavan linkage (2C-O-7C). The 13C NMR spectrum showed that procyanidins units are connected mostly by C4-C8 or C4-C6 interflavonoid bonds. Judging by a special diagnostic feature peak at $100.9 \mathrm{ppm}$ related to ketal carbon signal, proanthocyanidins contain doubly linked flavanyl units in the molecule (2C-O-7C) typical for A-type procyanidins (Figure 4).

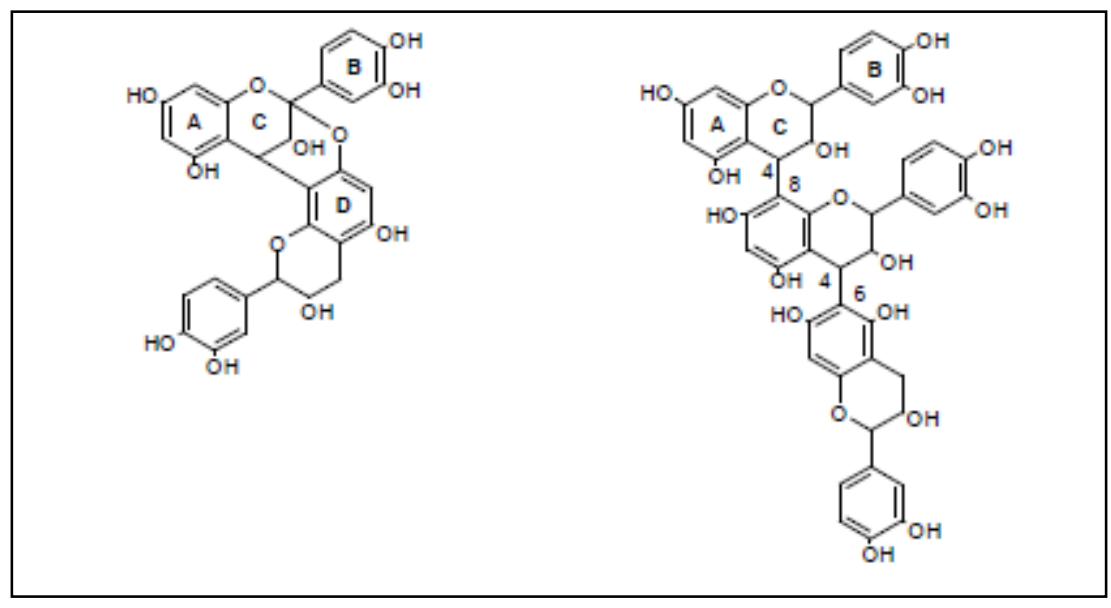

\section{Fig.2. Grey alder bark A-type procyanidine and C4-C8 and C4-C6 interflavanoid bonds containing procyanidine (B-type)}

The TOF-MS spectrum of proanthocyanidins showed that the molecular mass of proanthocyanidins polymers is not higher than $2018 \mathrm{Da}$ (Figure 4).

This value corresponds to the flavan-3-ol heptamer. Detection of the molecular ion $[\mathrm{M}-\mathrm{H}]^{-}$ with mass of $575 \mathrm{Da}$ confirmed the presence of A-type procyanidin in the composition of grey alder CT, whereas regular fragmentation in the range 288 - $2017 \mathrm{Da}$ gave evidence that oligomeric procyanidins composed by epicatechin units. Using TOF-MS electron spray negative ionization and NMR spectroscopy the grey alder bark condensed tannins were for the first time identified as a mixture of A- and B-type oligomeric procyanidins with the epicatechin units polymerization degree of 7 (Figures 3 and 4). 
Janceva S., Dizhbite T., Telisheva G., Spulle U., Klavinsh L., Dzenis M. TANNINS OF DECIDUOUS

TREES BARK AS A POTENTIAL SOURCE FOR OBTAINING ECOLOGICALLY SAFE WOOD ADHESIVES

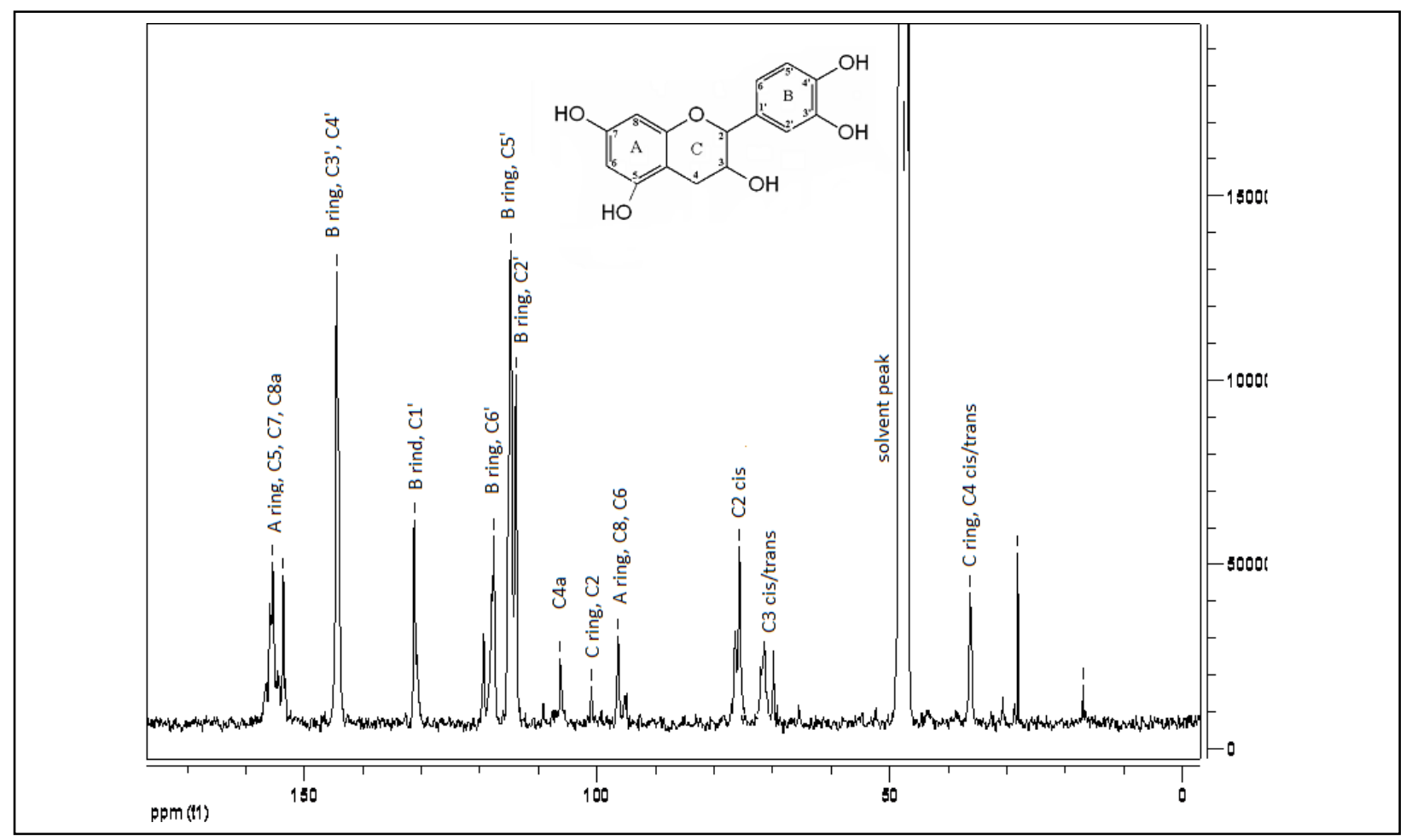

Fig.3. ${ }^{13}$ C-NMR spectrum of proanthocyanidins from grey alder bark

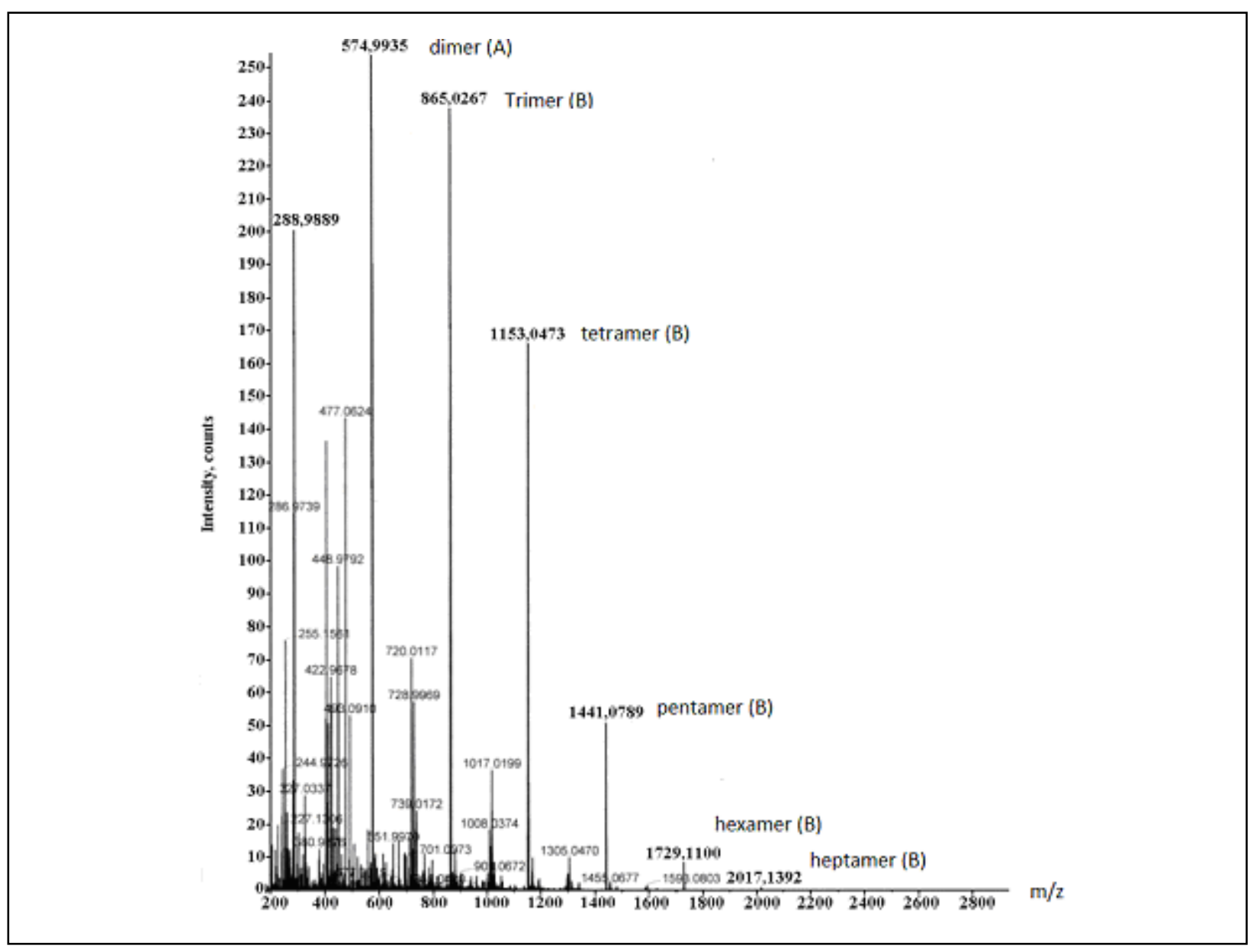

Fig.4. MS spectrum of proanthocyanidins from alder bark 
The test with stable organic radical $\mathrm{DPPH}^{\bullet}$ has been used for characterization of antioxidant activity of EtOH extract from alder bark as well as of the proanthocyanidins isolated from it. . Proanthocyanidins from Alnus incana bark showed the higher radical scavenging activity as compared with the reference standard Trolox. The $\mathrm{IC}_{50}$ values of proanthocyanidins, EtOH extract and Trolox were 3.1, 9.0 and $4.7 \mathrm{mg} / \mathrm{l}$, respectively. The proanthocyanidins concentration necessary for $50 \% \mathrm{DPPH}^{\bullet}$ inhibition was 1.5 times lower than that for the standard (Trolox).

Novel formaldehyde-free adhesives for wood material were obtained on the basis of rich-intannins EtOH extract from grey alder bark and aqueous PEI solutions.

The physico-mechanical characteristics of the tannin-PEI gels were investigated using DSC and the results obtained showed a large heat absorption peak at $\sim 120^{\circ} \mathrm{C}$, which indicated that the gel hardening proceeds in the temperature range $100-140^{\circ} \mathrm{C}$. Therefore, the temperature of $140^{\circ} \mathrm{C}$ was chosen for manufacture of plywood composite (Figure 5) from birch veneer by hot pressing.

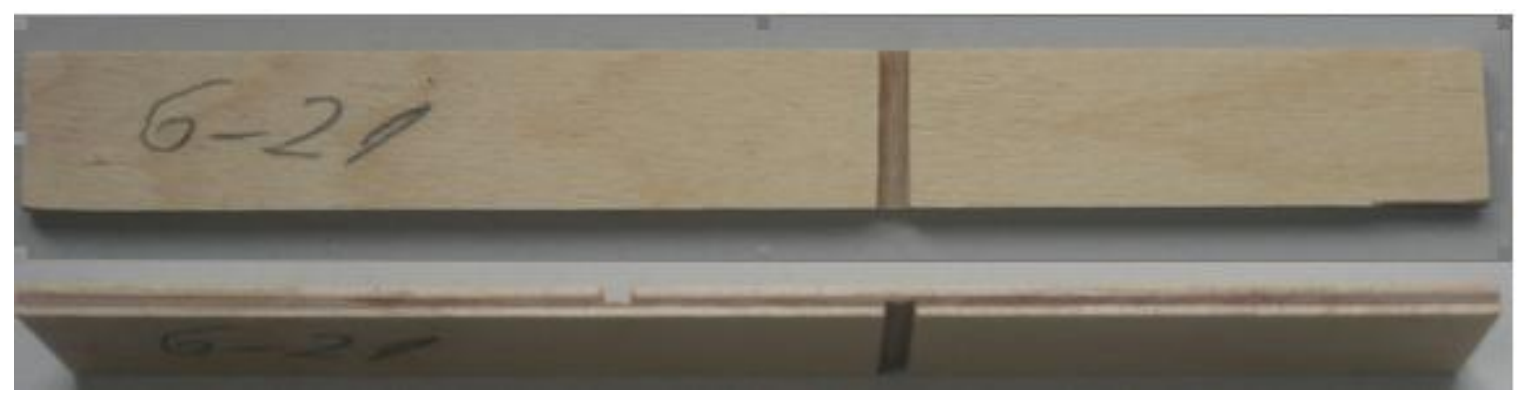

Fig.5. Plywood samples for tension shear test in accordance with the standard EN 314

\section{Table 1.}

Result of the test of glue and tannin-PEI adhesives on shear strength

\begin{tabular}{|c|c|c|c|c|}
\hline Mean values & \multicolumn{2}{|c|}{ Tannin based adhesive } & \multicolumn{2}{c|}{ PF resin adhesive } \\
\hline \multirow{2}{*}{$\mathrm{MR}\left(\mathrm{KN} / \mathrm{mm}^{2}\right)$} & longitudinal & transverse & longitudinal & transverse \\
\cline { 2 - 5 } & $21.9 \pm 0.7$ & $0.49 \pm 0.05$ & $13.6 \pm 0.8$ & $0.36 \pm 0.03$ \\
\hline
\end{tabular}

The results of the gluing quality tests of plywood composite (Table 1) showed that the mechanical properties of plywood glued using the CT-PEI based adhesives were higher than those for plywood glued using standard PF glues.

\section{Conclusions}

- The major components of aqueous ethanol extracts from Alnus sp. trees growing in Latvia are condensed tannins (up to $0.36 \mathrm{~g} / \mathrm{g}$ of hydrophilic extractives or $12.6 \%$ on bark dry mass). High portion of CT in polyphenolic pool of alder bark makes it a prospective raw material for industrial application.

- The grey alder bark condensed tannins were for the first time identified as a mixture of A- and B-type oligomeric procyanidins with the epicatechin units polymerization degree of 2-7.

- The antioxidant activity in the of grey alder proanthocyanidin in the test with DPPH free radical was 1.5 times higher than that for the standard (Trolox). 
- The rich-in-tannins EtOH extract have the high prospects for obtaining formaldehydefree adhesives for wood materials. The synthesized tannins-based adhesive provided 1.4 times increase in bending strength, in comparison with conventional phenolformaldehyde resins.

\section{Acknowledgement}

The financial supports from the EU Development Funding 2.1.1.1 "Support to Science Research" (Project Nr.2010/0241/2DP/2.1.1.1.0/10/APIA/VIAA/006), Latvian National Programme 3.2.5 (4-2) and Latvian Research Grant 1547 are gratefully acknowledged.

\section{References}

1. Teliševa G., Dižbite T., Bikovens O., Krasiļnikova J. Baltalkšņa miza ka izejviela bioloǵiski aktīvu poilifenolu, ķīmikāliju un sorbentu iegūšanai. Rakstu krājums „Lapu koku audzēšanas un racionālas izmantošanas pamatojums, jauni produkti un tehnologijas”, R̄̄ga, LV KĶI, 2009, 170-174 lpp.

2. Tondi, G., Pizzi, A.Tannin-based ragid foams: Characterization and modification. Ind. Grops Prod., 29, 2009 , p. 356.

3. Scalbert, A. Antimicrobial properties of tannins. Phytochem., 30, 1991, pp. 3875-3883.

4. Gu, L., Kelm, M.A., Hamerstone, J.F., Beecher, G., Holden, J., Hautowitz, D., Prior, R.L. Screening of food containing proanthocyanidins and their structural characterization using LC-MS/MS thiolytic degradation. J. Agric. Food Chem., 51, 2003, p. 513.

5. Waterhouse, A.L Determination of total phenolics. Food sci., 2, 2000, p. 567.

6. Schofield P.D., Mbugua, M., Pell, A.N. Analysis of condensed tannins: a review. Anim. Sci. Technol., 91, 2001, pp. 21-40.

7. Miliauskas, G., Venskutonis, P.R., Van Beek, T.A. Screening of radical scavenging activity of some medicinal and aromatic plant extracts. Food Chem, 85, 2004, pp. 231-237.

8. Li, K., Geng, X., Simonsen, J., Karchesy, J. Novel wood adhesives from condensed tannins and polyethylenimine. J. Adhes. Adhes., 24, 2003, pp. 327-333.

9. Zanuttini, R., Cremonini, C. Optimization of the test method for determining the bonding quality of core plywood (blackboard). Mater. Struct., 35, 2002, pp. 126-132.

10. Novarette, P., Pizzi, A., Pasch, H., Rode, K., Delmotte, L. MALDI-TOF and ${ }^{13}$ C-NMR characterization of maritime pine industrial tannin extract., Ind. Grops Prod, 32, 2010, p. 106. 